\title{
A Structural Vector Autoregressive Model of Technical Efficiency and Delays with an Application to Chinese Airlines
}

\begin{abstract}
This study reports on the performance assessment of Chinese airlines from 20062014 using a stochastic distance function where technical efficiency and a measure of flight delays follow a joint structural autoregressive process. This model is used to investigate whether technical efficiency causes flight punctuality or the other way around. The model, however, yields a non-trivial likelihood function and is not amenable to estimation using least squares or standard maximum likelihood techniques. To estimate the model therefore, we propose and implement maximum simulated likelihood with importance sampling. The results suggest a mutual dependence (feedback) between technical efficiency and delays. Policy implications are derived.
\end{abstract}

Keywords: stochastic distance function; SVAR; China; airlines; technical efficiency; delays.

\section{Introduction}

The complexity of air transport operations and their underlying services represents a growing study field in light of the innumerous challenges derived from increased airline competition and airport (de)regulation verified in the past decades (Graham, 2008). In fact, although the need for continuous performance measurement and monitoring is wellacknowledged by academics and practitioners (Bitzan et al., 2016), there is still room opened for including negative externalities imposed to customers when assessing performance levels of air transport operations (Assaf et al., 2014).

This research focuses on the technical efficiency of Chinese airlines by using a novel Structural Vector Autoregressive (SVAR) model of technical efficiency and delays built upon a stochastic distance function. It differs from previous research on airline efficiency that have used several methods such as (i) factor productivity approach (Bauer, 1990; Oum and Yu, 1995. Barbot et al., 2008); (ii) Stochastic Frontier Analysis or SFA models (Good et al, 1993, 
Baltagi et al., 1995); (iii) Tornquist total factor productivity index (Coelli et al., 2003; Barbot et al., 2008); (iv) Data Envelopment Analysis or DEA models (Merkert and Hensher, 2011; Barros et al., 2013; Barros and Peypoch, 2009; Barros and Couto, 2013; Wanke and Barros, 2016b); and (v) multi-criteria decision-making models such as TOPSIS (Barros and Wanke, 2015; Wanke et al., 2015). All these papers analyzed airlines from the US (Barros et al., 2013; Greer, 2008; Sjögren and Söderberg, 2011), Canada (Bauer, 1990; Assaf, 2009), Europe (Distexhe and Perelman, 1994; Greer, 2008; Barros and Peypoch, 2009), Asia (Baltagi et al., 1995; Wanke et al., 2015), Africa (Barros and Wanke, 2015), and Latin America (Wanke and Barros, 2016b).

Given the relative importance of China to the world economy, it is possible to affirm that Chinese airlines consist of a relatively understudied topic. As a matter of fact, only a few studies were devoted to this particular industry (Chow, 2010 and Wu et al., 2013; Wanke et al., 2015).

On the other hand, it is worth noting that, within the airline efficiency ambit, DEAbased studies are the most numerous when compared to the SFA-based methods and other minor approaches used (Wanke et al., 2015; Barros and Wanke, 2015; Wanke and Barros, 2016a, 2016b). This not only replicates a pattern that is found in papers focused on efficiency analysis in other industries such as ports and banking (e.g. Wanke et al., 2016a, 2016b), but may be also derived by the flexibility provided by DEA models in handling two-stage analysis where scores are computed first and statistically tested subsequently. In fact, several different issues have been addressed by DEA-based airline research studies in different countries or regions. Besides efficiency rankings and slack comparisons, it is possible to point out, for instance, that the impacts of network size, ownership, and regulatory measures on the performance of the airline industry have been addressed by regressing efficiency scores onto contextual or environmental variables (Barros et al., 2013; Barros and Wanke, 2015).

Recent papers maintain this focus (Wanke and Barros, 2016a, 2016b), although it is important to mention that the cross-impact of the quality of the services provided on airline efficiency is still understudied. To the best of our knowledge, as regards airline efficiency, only Wanke et al. (2015) addressed the issue between quality of the services provided and technical efficiency within the ambit of the airline industry in Asia. The authors found a positive, albeit weak, relationship between higher levels of service quality and efficiency. This result may suggest the existence of a trade-in between operational/financial efficiency and 
service quality, different from the classical trade-off between efficiency and service where higher levels of service are obtained to the detriment of lower levels of efficiency.

Therefore, this paper builds upon the existing body of knowledge by presenting a novel SVAR model for technical efficiency and delays in the ambit of the Chinese airline industry. Not only is China one of the fastest growing areas in the world, which justifies the relevance of this study, but this paper also fills a literature gap by presenting and developing a novel stochastic distance function where delays - the quality measure used in this research - are simultaneously computed with airline technical efficiency scores in a single-stage procedure. This is particularly important due to the endogenous nature of some quality metrics: they do not only affect the efficiency levels of the productive process, but they are also affected by them in a feedback loop. In fact, flight delays are rather studied within the ambit of airport operations as an undesirable output by means of DEA and its variants, thus suggesting the opportunity to address this phenomena at the airline level using stochastic autoregressive models (Yu, 2004; Yu, 2010; Lozano and Gutierrez, 2011; Lozano et al., 2013; Assaf et al., 2014).

This research also lends a contribution to the business or practical side or air transport operation. From a customer service viewpoint, flight delays not only impose costs on passengers but also on airlines, by forcing both to use more resources to accomplish the same output: flying in a timely manner (Assaf et al., 2014). In fact, passengers may obtain less value from a trip as they are forced to wait out delays in airports, while increasing the potential switching decision to move to another airline and negative word of mouth (Gustafsson, 2009; Aaker et al., 2004).

The paper is structured as follows: after this introduction, the background on the Chinese aviation industry is presented including a description of the Chinese airlines. The literature survey is then presented followed by the methodology section where the SVAR model for technical efficiency and delays is further discussed. Section 5 presents the discussion of the results. Conclusions are presented in Section 6.

\section{Background on Chinese Airlines}

The backgrounds of the Chinese civil aviation industry are depicted in the next paragraphs. Similarly to what happened in different countries around the world, the scenario 
of few airlines that existed decades ago moved from a tight state control and ownership to a large number different players embedded in a more flexible regulatory environment. Such huge changes over the course of a couple of decades impose the need to assure that the current governance/regulatory combination practices lead to the best performance in the air transportation industry (Assaf et al., 2014). In fact, as further depicted, it appears that negative externalities, such as flight delays, are rapidly increasing in the Chinese airline industry. They should be taken into consideration in order to provide an accurate picture in terms the relative performance of their companies. The correct acknowledgment of these undesirable effects are relevant for the establishment of sound regulatory/governance policies.

The Chinese civil aviation industry was relatively undeveloped until 1978, at which time the government embarked on a policy of reform by opening it up and switching it to a market-oriented economy. During the last three decades, China has witnessed the blossoming of its economy, increased trade with other countries around the world, and rapid growth of civil aviation. The economic globalization and regionalization of production after entering the World Trade Organization (WTO) has driven the growth of Chinese aviation business to a further wave of development (cf. Figure 1). At present, China has been the second largest aviation market in the world in terms of the volumes of passengers and air cargo moved in its domestic market since 2007 (Jiang and Zhang, 2016; Chen et al., 2017).

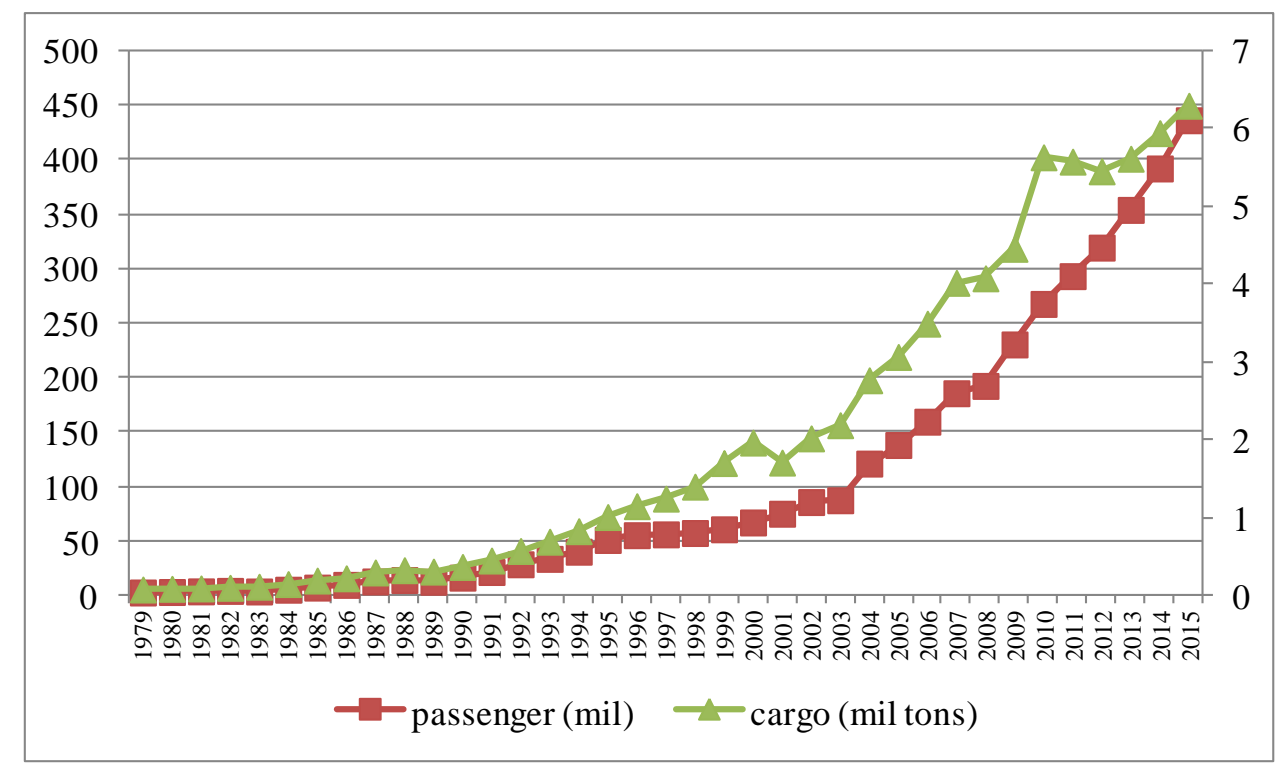

Figure 1: The development of Chinese civil aviation $(\mathrm{mil}=$ million $)$

The quick development of the airline sector has greatly contributed the prosperity of the Chinese civil aviation industry nowadays. However, before the year of 1978, air transportation was fully and tightly controlled by the central government under the CAAC, 
which operated in a military or semi-military style, collaborating with the Air Force of China (Shaw et al., 2009; Wang et al., 2016). After 1978, the government successively established six state-owned airline companies ${ }^{1}$, which were separated from the CAAC and reduced government intervention. To decrease the monopoly power of the civil aviation industry, some new airline companies founded by the local governments or government-owned enterprises also entered the market during this stage (Jiang and Zhang, 2016). Meanwhile, the CAAC allowed airlines to adopt price discrimination to improve competition in 1997. Foreign investment in the civil aviation sector was also permitted. In 2005, the CAAC further deregulate the Chinese civil aviation sector and opened it to private investors and the number of private airlines has grown rapidly (Wang et al., 2016), including a low-cost carrier. To enhance efficiency and competitiveness, market-driven consolidation also took place during this period, especially after the Asian financial crisis as well as the global financial crisis that broke out since 2007. Through merging and acquisition, the "Big three", i.e. Air China, China Southern, and China Eastern, have seized most of the market share in the domestic civil aviation sector (Lei and O’Connell, 2011).

Despite experiencing high-speed development of civil aviation business and great improvement on corporate governance of airline companies, the flight delays have been one of the major sources of passenger complaints in China, and the civil aviation authority has determined to improve the situation (Vlachos and Lin, 2014). As shown by Figure 2, the overall punctuality of Chinese civil aviation has significantly dropped down during recent years, especially after 2009. Moreover, punctuality has gotten even worse from 2014 to 2015, reaching levels lower than $60 \%$. Flight delay is not only one of the main drivers to service quality and customer loyalty (Vlachos and Lin, 2014; Zhang et al., 2015), but it also is an important indicator suggesting the status and performance of airline companies (Fan et al., 2014).

\footnotetext{
${ }^{1}$ Included Air China, China Eastern Airlines, China Southern Airlines, China Southwest Airlines, China Northwest Airlines, and China Northern Airlines.
} 


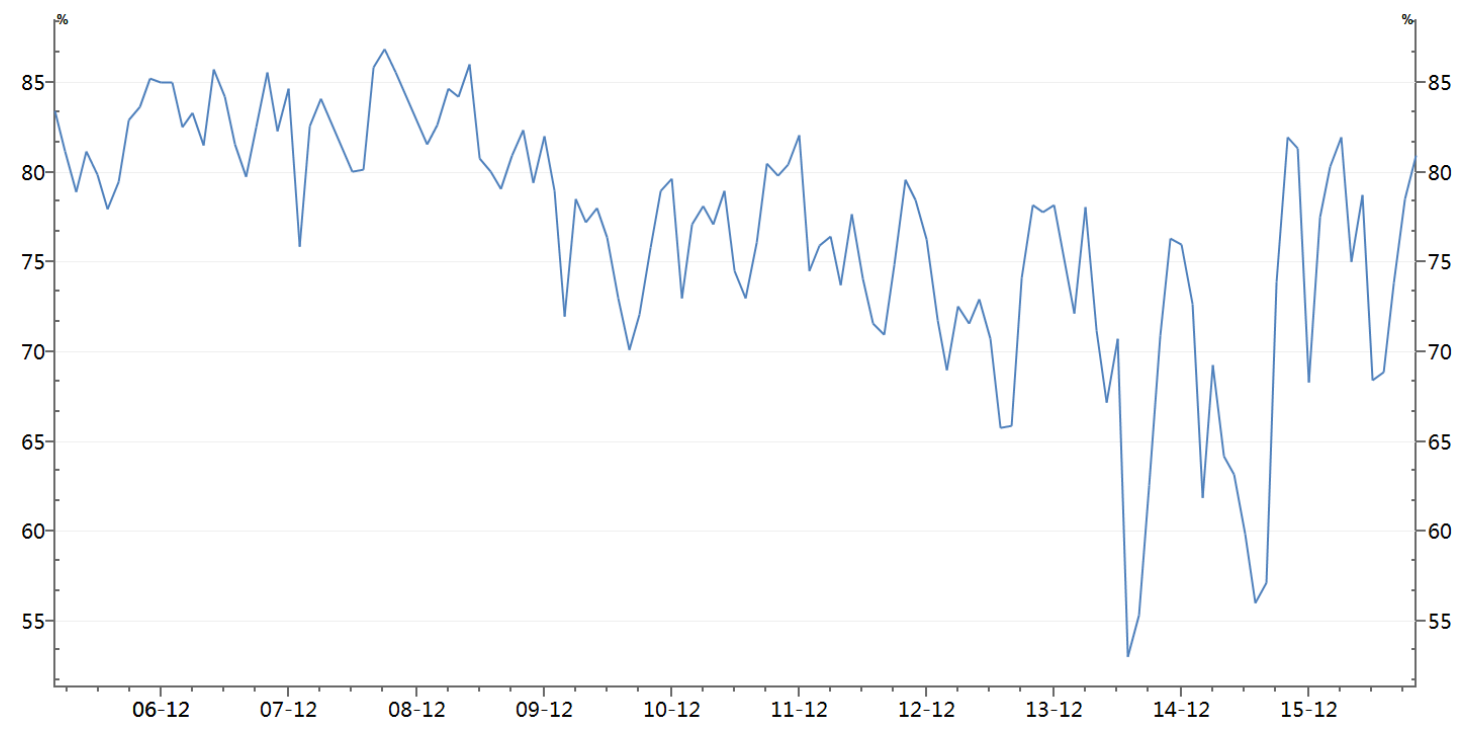

Figure 2: overall punctuality of Chinese civil aviation.

Sources: WIND database.

\section{Literature Review}

Although the civil aviation industry has played an essential role in Chinese economy, research on the efficiency of Chinese airline companies is rather limited. Wanke et al. (2015) use TOPSIS to assess the performance of the Asian airlines, including several Chinese airline companies. Meanwhile, it further applies GLMM-MCMC methods to assess the impact of contextual variables on efficiency. The results reveal significant impacts of cost structure, ownership type, market positioning, and mileage program offered on efficiency levels. Wang et al. (2014) compute the leading Chinese airlines' productivity and benchmark them against major airlines around the world. It finally finds that Chinese airlines' productivity has improved significantly in the past decade, but still lags behind that of industry leaders. Meanwhile, Cui and $\mathrm{Li} \mathrm{(2015)} \mathrm{use} \mathrm{DEA} \mathrm{and} \mathrm{the} \mathrm{Malmquist} \mathrm{index} \mathrm{to} \mathrm{calculate} \mathrm{the} \mathrm{civil} \mathrm{aviation} \mathrm{safety} \mathrm{efficiency}$ of ten Chinese airline companies from 2008 to 2012, and the Panel Regression Model is used to identify the important influencing factors on civil aviation safety efficiency. Wu et al. (2013) employ DEA to evaluate the operational efficiency and a bootstrapped truncated regression to explore the impact of environmental variables on efficiency of Chinese and non-Chinese airlines. However, the research has not considered service quality such as flight delay, etc. Furthermore, most of the research just adopts a traditional DEA model to estimate the efficiency and covers a small proportion of airline companies in China. 
Flight delays have been given much attention by some civil aviation management scholars (Vlachos and Lin, 2014; Jiang and Zhang, 2016). Fan et al. (2014) employs a directional distance function to evaluate the technical efficiency within a joint production framework of desirable and undesirable output (i.e. flight delays). However, it only examined twenty major Chinese airports from 2006 to 2009, rather than the airline companies.

In fact, research on Chinese airline efficiency represents a small fraction of the overall research produced with respect to airline efficiency in different countries or regions. A literature review synthesis is presented in Table 1, which enumerates the objects of analysis and the models used in each paper over the last three decades of studies on airline efficiency. Taking a closer look within each paper, one can easily note that the most common inputs are labor, capital, and materials or capacity, while the most frequent outputs include revenues, profits, movements, and passengers. Therefore, in this research and in consonance with previous researches, the inputs used are number of employees, total number of planes, and the fuel consumed. The outputs are the total number of passengers carried and the total cargo transported. Furthermore, it should be noted that thus far no paper has adopted a method that simultaneously computes airline efficiency scores considering flight delays in a stochastic fashion. Furthermore, except for Wanke et al. (2015), no paper has performed an efficiency analysis focusing also on service quality within the ambit of the airline industry, which is an additional contribution of this paper.

Table 1: Literature review

\begin{tabular}{|l|l|l|}
\hline Author(s) & $\begin{array}{l}\text { Focus of analysis and sample } \\
\text { sizes }\end{array}$ & Method(s) used \\
\hline Caves et al. (1981) & 15 US airlines & Multilateral TFP index \\
\hline Caves et al. (1984) & 9 US airline & Translog Cost Frontier \\
\hline $\begin{array}{l}\text { Schmidt and Sickles } \\
(1984)\end{array}$ & Largest US airlines & $\begin{array}{l}\text { Cobb-Douglas Production } \\
\text { Function }\end{array}$ \\
\hline Bauer (1990) & 7 Canadian airlines & Translog Cost Frontier \\
\hline Gillen et al. (1990) & 8 US airlines & Translog cost Regression \\
\hline Cornwell et al. (1990) & $\begin{array}{l}\text { 14 US and 27 international } \\
\text { airlines }\end{array}$ & $\begin{array}{l}\text { Cobb-Douglas Production } \\
\text { Frontier }\end{array}$ \\
\hline
\end{tabular}




\begin{tabular}{|c|c|c|}
\hline Windle (1991) & Largest US airlines & $\begin{array}{l}\text { Multilateral TFP Index and } \\
\text { Cost Function }\end{array}$ \\
\hline Windle (1991) & Largest US airlines & $\begin{array}{l}\text { Multilateral TFP Index and } \\
\text { Cost Function }\end{array}$ \\
\hline Good et al. (1993) & $\begin{array}{l}9 \text { US, } 15 \text { European and } 9 \text { Asian } \\
\text { airlines }\end{array}$ & $\begin{array}{l}\text { Cobb-Douglas Production } \\
\text { Frontier }\end{array}$ \\
\hline $\begin{array}{l}\text { Distexhe and Perelman } \\
\text { (1994) }\end{array}$ & US and European airlines & $\begin{array}{l}\text { DEA-CCR and Malmquist } \\
\text { Index }\end{array}$ \\
\hline Good et al. (1995) & US airlines & $\begin{array}{l}\text { Cobb-Douglas Production } \\
\text { Frontier and DEA-CCR }\end{array}$ \\
\hline Baltagi et al. (1995) & 8 US, 8 European and 7 Asian & $\begin{array}{ll}\text { Translog Variable Cost } \\
\text { Function }\end{array}$ \\
\hline Oum and Yu (1995) & 32 international airlines & Multilateral TFP Index \\
\hline Coelli et al. (1999) & 11 US airlines & $\begin{array}{l}\text { Translog Production } \\
\text { Frontier }\end{array}$ \\
\hline Liu and Lynk (1999) & $\begin{array}{l}18 \text { international airlines, } 20 \\
\text { international airlines }\end{array}$ & $\begin{array}{l}\text { Cobb-Douglas } \quad \text { Cost; } \\
\text { Malmquist Productivity } \\
\text { Index }\end{array}$ \\
\hline Inglada et al. (2006) & 39 International airlines & DEA-BCC and TFP Index \\
\hline Barbot et al. (2008) & 14 US airlines & DEA-BCC and TFP Index \\
\hline Greer (2008) & 8 US airlines & $\begin{array}{l}\text { DEA-CCR and Two Stage } \\
\text { Regression }\end{array}$ \\
\hline Greer (2009) & 29 European airlines & Malmquist Index \\
\hline $\begin{array}{l}\text { Barros and Peypoch } \\
(2009)\end{array}$ & 12 US airlines & $\begin{array}{l}\text { DEA-CCR and two Stage } \\
\text { regression }\end{array}$ \\
\hline Assaf (2009) & 7 Canadian Airlines & $\begin{array}{l}\text { Stochastic Production } \\
\text { Bayesian Frontier }\end{array}$ \\
\hline Ouellette et al. (2010) & 50 largest airlines & $\begin{array}{l}\text { Technical Efficiency and } \\
\text { Allocative Efficiency }\end{array}$ \\
\hline Chow (2010) & Chinese airlines, 2003-2007 & $\begin{array}{l}\text { Efficiency analyzed with } \\
\text { DEA and Productivity }\end{array}$ \\
\hline
\end{tabular}




\begin{tabular}{|c|c|c|}
\hline & & $\begin{array}{l}\text { analyzed with Malmquist } \\
\text { Index }\end{array}$ \\
\hline $\begin{array}{l}\text { Sjögren and Söderberg } \\
(2011)\end{array}$ & 18 major UK airlines & Input Distance Function \\
\hline $\begin{array}{l}\text { Merkert and Hensher } \\
\text { (2011) }\end{array}$ & 15 US airlines & DEA Two Stage \\
\hline Barros and Couto (2013) & 23 European airlines & $\begin{array}{l}\text { Malmquist and Luenberger } \\
\text { Productivity Measures }\end{array}$ \\
\hline $\begin{array}{l}\text { Bilotkach and Huschelrath } \\
\text { (2012) }\end{array}$ & Airline alliances & Conceptual Approach \\
\hline Barros et al. (2013) & $\begin{array}{l}\text { 11 USA airlines from } 1998 \\
\text { to } 2010\end{array}$ & B-convex DEA Model \\
\hline Wu et al. (2013) & $\begin{array}{l}\text { Chinese airlines, other Asian } \\
\text { airlines, USA airlines and } \\
\text { European airlines, 2006-2010 }\end{array}$ & $\begin{array}{l}\text { Efficiency with CCR and } \\
\text { BCC DEA Model and a } \\
\text { Second-stage Regression } \\
\text { explaining efficiency. }\end{array}$ \\
\hline Tavassoli et al. (2014) & Iranian airlines in 2010 & $\begin{array}{l}\text { SBM-NDEA Model } \\
\text { (Slacks Based Measure } \\
\text { Network Data Envelopment } \\
\text { Analysis) }\end{array}$ \\
\hline $\begin{array}{l}\text { Lee and Worthington } \\
(2014)\end{array}$ & Several airlines, 1994-2011 & $\begin{array}{l}\text { DEA and SFA and Second- } \\
\text { Stage Regression }\end{array}$ \\
\hline Barros and Wanke (2015) & African airlines, 2010-2013 & $\begin{array}{l}\text { TOPSIS and Neural } \\
\text { Networks in a Two-stage } \\
\text { Approach }\end{array}$ \\
\hline Wanke et al. (2015) & Asian airlines, 2006-2012 & $\begin{array}{l}\text { TOPSIS and GLMM- } \\
\text { MCMC in a Two-stage } \\
\text { Approach }\end{array}$ \\
\hline Wanke and Barros (2016) & $\begin{array}{l}\text { Latin American airlines, 2010- } \\
2014\end{array}$ & $\begin{array}{l}\text { Virtual Frontier Dynamic } \\
\text { DEA and Simplex } \\
\text { Regression in a Two-stage } \\
\text { Approach }\end{array}$ \\
\hline
\end{tabular}




\section{Methodology}

\subsection{The Data}

The data on nine selected Chinese airlines were obtained from the Wind (www.wind.com.cn/) database and their annual financial reports on the website of Shanghai Stock Exchange (www.sse.com.cn) and Shenzhen Stock Exchange (www.szse.cn) for the period 2006 to 2014. The descriptive statistics for their productive resources-inputs and outputs as depicted in Section 3-and their average flight delays are presented in Table 2.

Table 2: Descriptive statistics for the Chinese airlines productive resources and delays (*)

\begin{tabular}{|c|c|c|c|c|c|}
\hline Variables & Min & Max & Mean & SD & CV \\
\hline number of employees & 131.000 & 97548.000 & 16875.436 & 26047.884 & 1.544 \\
\hline fuel (tons) & 793.000 & 5729424.000 & 967390.376 & 1442100.269 & 1.491 \\
\hline number of planes & 2.000 & 500.000 & 96.368 & 136.178 & 1.413 \\
\hline cargo (tons) & 436.300 & 1146728.900 & 215710.920 & 289183.463 & 1.341 \\
\hline number of passengers & 0.000 & 70611294.000 & 14287796.735 & 18966695.253 & 1.327 \\
\hline delay (proportion being on time, \%) & 43.037 & 85.093 & 71.706 & 10.467 & 0.146 \\
\hline
\end{tabular}

(*) Readers should note that Donghai Airlines and China Post Air do not operate passenger traffic, which is why the minimal number of passengers is zero.

\subsection{Econometric Model}

The first model is a standard output distance function of the form:

$D(x, y)=1$,

where $x \in R^{K}$ denotes the inputs and $y \in R^{M}$ denotes the outputs in log form. Using linear homogeneity with respect to outputs and introducing and error term along with technical inefficiency, we have:

$y_{1, i t}=f y_{(-1), i t}, x_{i t}+v_{i t}-u_{i t}, i=1, \ldots, n, t=1, \ldots, T$,

where $y_{(-1), i t}=\left[y_{2, i t}, \ldots, y_{M, i t}\right]^{\prime}, v_{i t}$ is an error term, $u_{i t} \geq 0$ denotes technical inefficiency.

Suppose $z_{i t} \in R^{p}$ is a vector of environmental variables such as those related to quality, delay, etc. In the standard approach, one either makes $\mathrm{u}$ a function of $\mathrm{z}$ or regresses $\mathrm{z}$ on estimated $\mathrm{u}$. The latter approach is known to yield biased estimates while the former is too restrictive 
(Kumbhakar and Lovell, 2000). In Model I we assume: $u_{i t} \sim N_{+} a_{0}+a_{1} z_{i t}, \sigma_{u}^{2}$. In particular, we assume $\mathrm{p}=1$ and $\mathrm{z}$ is delay, which is a measure of quality.

In Model II we use a more elaborate model to investigate the direction of causality between delays and technical inefficiency using a dynamic model, which is estimated along with (2). The dynamic model has the following form:

$$
\begin{aligned}
& z_{i t}=c_{10}+\alpha_{11} z_{i, t-1}+\alpha_{1 L} z_{i, t-L}+\beta_{10} u_{i t}+\beta_{11} u_{i, t-1}+\ldots+\beta_{1 L} u_{i, t-L}+\varepsilon_{i t, 1}, \\
& u_{i t}=c_{20}+\alpha_{20} z_{i t}+\alpha_{21} z_{i, t-1}+\alpha_{2 L} z_{i, t-L}+\beta_{21} u_{i, t-1}+\ldots+\beta_{2 L} u_{i, t-L}+\varepsilon_{i t, 2},
\end{aligned}
$$

where $\varepsilon_{i t}=\left[\varepsilon_{i t, 1}, \varepsilon_{i t, 2}\right]^{\prime}$ is an error term. This system is a structural vector autoregression (SVAR) relating technical inefficiency and delays. Apart from that, we complete (2) using a reduced form equation for $y_{(-1), i t}$ as follows:

$y_{(-1), i t}=\Pi_{x} x_{i t}+\Pi_{w} w_{i t}+\pi_{z} z_{i t} \mathbf{1}+\varepsilon_{(-1), i t}$,

where $w_{i t} \in R^{q}$ is a vector of exogenous variables (firm and time dummies), $\Pi_{x}$ is an $M \times K$ matrix, $\Pi_{w}$ is an $M \times q$ matrix, $\pi_{z}$ is a scalar coefficient, and $\mathbf{1}$ is a vector of ones in $R^{M-1}$.

The endogenous variables are $y_{1, i t}, y_{(-1), i t}, z_{i t}$ and $u_{i t}$. We assume that inputs are predetermined as we use an output distance function. The Jacobian of transformation in the system consisting of (2), (3), (4), and (5) is

$J=\left|1-\alpha_{20} \beta_{10}\right|$

If we assume

$v_{i t} \sim i i d N \quad 0, \sigma_{v}^{2}, \varepsilon_{i t} \sim i i d N_{2}(0, \Omega), \varepsilon_{(-1), i t} \sim i i d N_{M-1}(0, \Sigma)$

and these error terms are mutually independent, the likelihood function of the system consisting of (2), (3), (4), and (5) is given by: 


$$
\begin{aligned}
& L \theta ; Y=\int_{R_{+}^{n T}} 2 \pi \sigma_{v}^{2}{ }^{-n T / 2} \exp -\frac{1}{2 \sigma_{v}^{2}} \sum_{i=1}^{n} \sum_{t=1}^{T} y_{1, i t}-f\left(y_{(-1), i t}, x_{i t}\right)+u_{i t}{ }^{2} \cdot\left|1-\alpha_{20} \beta_{10}\right|^{n T / 2} . \\
& 2 \pi^{-1 / 2}|\Omega|^{-n T / 2} \exp -\frac{1}{2} \varepsilon_{i t}^{\prime}(\theta) \Omega^{-1} \varepsilon_{i t}(\theta) . \\
& 2 \pi^{-(M-1) / 2}|\Sigma|^{-n T / 2} \exp \left\{-\frac{1}{2} y_{(-1), i t}-\Pi W_{i t}^{\prime} \Sigma^{-1} y_{(-1), i t}-\Pi_{x} W_{i t}\right\} d \mathbf{u},
\end{aligned}
$$

where $\quad \varepsilon_{i t} \theta=\left[\begin{array}{l}z_{i t}-c_{10}-\alpha_{11} z_{i, t-1}-\alpha_{1 L} z_{i, t-L}-\beta_{10} u_{i t}-\beta_{11} u_{i, t-1}-\ldots-\beta_{1 L} u_{i, t-L} \\ u_{i t}=c_{20}+\alpha_{20} z_{i t}+\alpha_{21} z_{i, t-1}+\alpha_{2 L} z_{i, t-L}+\beta_{21} u_{i, t-1}+\ldots+\beta_{2 L} u_{i, t-L}+\varepsilon_{i t, 2}\end{array}\right]$, $W_{i t}=\left[x_{i t}, w_{i t}, z_{i t}\right], \Pi=\left[\Pi_{x}, \Pi_{w}, \pi_{z} \mathbf{1}\right]$, and the integration is with respect to $\mathbf{u}=\left[u_{i t}\right] \in R_{+}^{n T}$. Here, $\theta \in R^{d}$ is the entire parameter vector and $Y$ denotes the data. The multivariate integration is quite complicated because of the dynamic dependence in (3a) and (3b). A standard translog for flexibility was chosen for the functional form $f\left(y_{(-1), i t}, x_{i t}\right)$.

To maximize (6) we use importance sampling followed by a Gauss-Newton numerical maximization procedure. Importance sampling is based on the idea that when we must compute an integral of the form $I=\int L(\mathbf{u}) d \mathbf{u}$ we can always write it in the form:

$$
I=\int \frac{L(\mathbf{u})}{q(\mathbf{u})} q(\mathbf{u}) d \mathbf{u}
$$

where $q(\mathbf{u})$ is an importance density. If a sample of random numbers $\mathbf{u}^{(s)}, s=1, \ldots, S$ can be drawn from the importance density ${ }^{2}$, then $I \simeq S^{-1} \sum_{s=1}^{S} \frac{L\left(\mathbf{u}^{(s)}\right)}{q\left(\mathbf{u}^{(s)}\right)}$. To construct our importance density, we use a multivariate truncated normal distribution $\mathbf{u} \approx N_{+}^{n T} \mathbf{m}, \mathbf{V}$ and we optimize $\mathbf{m}, \mathbf{V}$ so that it is as close to (6) as possible in the Kullback-Leibler sense, so we first solve the problem:

\footnotetext{
2 Although the sample size is relatively small, we did not notice any convergence issues. In fact, the small sample results in faster convergence due to our use of a conjugate gradient algorithm. Convergence was facilitated, by a choice of initial conditions using 10,000 random searches to obtain good starting values before initializing the conjugate gradient algorithm.
} 
$\min _{\mathbf{m}, \mathbf{V}}: \int q(\mathbf{u}) \log \frac{q(\mathbf{u})}{L(\mathbf{u})} d \mathbf{u} \simeq S^{-1} \sum_{s=1}^{S} \log \frac{q\left(\mathbf{u}^{(s)}\right)}{L\left(\mathbf{u}^{(s)}\right)}$

where $\mathbf{u}^{(s)}, s=1, \ldots, S$ is a sample from $q(\mathbf{u})$, the density of $N_{+}^{n T} \mathbf{m}, \mathbf{V}$ in this instance, and $L(\mathbf{u})$ is the integrand in (6).

It is worth mentioning that the proposed model is a novel one that couples a distance function with a vector autoregressive model for technical inefficiency and a vector of covariates z. This removes the assumption that technical inefficiency is static as we adopt a dynamic framework and it relates it explicitly, and in a dynamic way, to certain covariates $z$. The traditional model simply assumes that technical inefficiency is i.i.d. In other contexts, inefficiency has been assumed to depend on certain covariates (Battese-Coelli model) and, finally, there are the Tsionas $(2002,2006)$ models where technical inefficiency follows an autoregressive scheme. Here, we nest all these models by proposing a novel SVAR model for $\mathrm{z}$ and technical inefficiency to compute impulse response functions, which is what we really need in our context. Codes were developed in Fortran 77.

\section{Analysis and Discussion of Results}

The technical efficiency levels calculated for nine selected Chinese airlines from 2006 to 2014, using the SVAR model for the technical efficiency and delays (model II), are given in Figure 3, which also depicts the scores computed for the traditional stochastic distance function (model I). These results suggest that the discriminatory power of the SVAR model is higher than those observed in traditional stochastic models because their scores are lower. While in model I average scores for technical efficiency are higher and appear to be increasing over the course of time, when the effect of delays is simultaneously considered in the variance of the residuals, technical efficiency scores are not only deflated, but also remain fluctuating around 0.60 . 


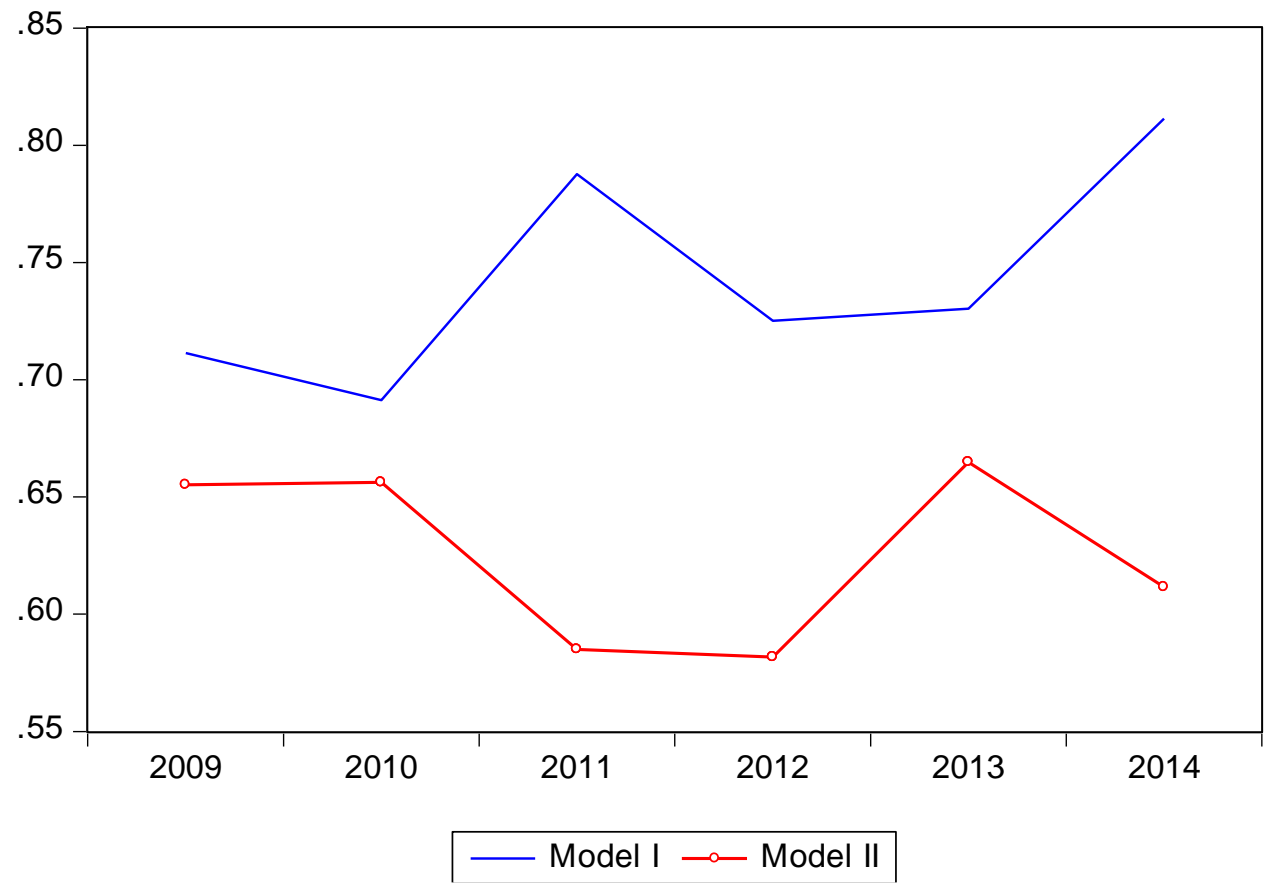

Figure 3. Average efficiency over time.

As regards the cause-effect relationship between technical efficiency and flight delays, the impulse responses presented in Figure 4 reveal a mutual dependence (feedback) between both variables. Putting it into other words, higher efficiency levels (lower technical inefficiency) are correlated with lower delays, although no possible claim can be made with respect to which variable is the cause and which one is the effect. This being the case, the underlying proposition of this study is related to the fact that higher airline efficiency levels present a positive impact on operational planning and execution on a daily-basis, which in turn, by presenting lower delays, contributes with a better asset utilization to meet demand needs. That is, lower delays contribute to a better match between productive resources and consumption, thus contributing to higher efficiency levels. 
GIRF of $U$ to $U$

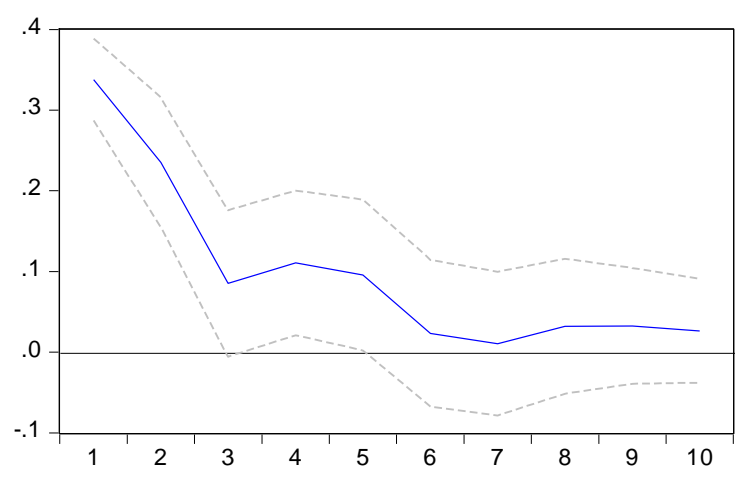

GIRF of $Z$ to $U$

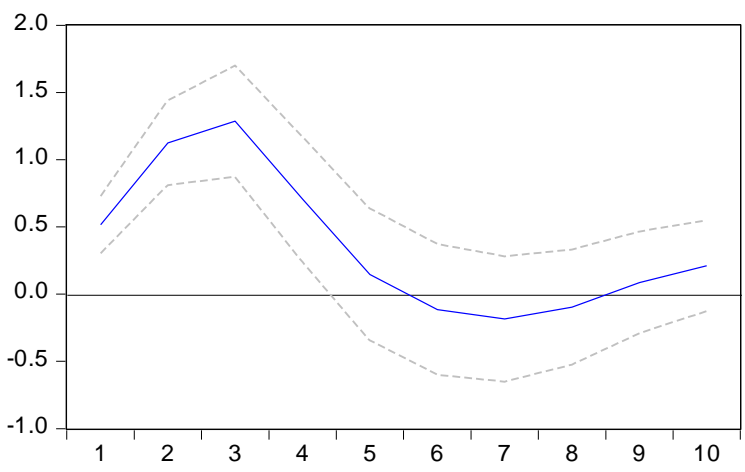

GIRF of $U$ to $Z$

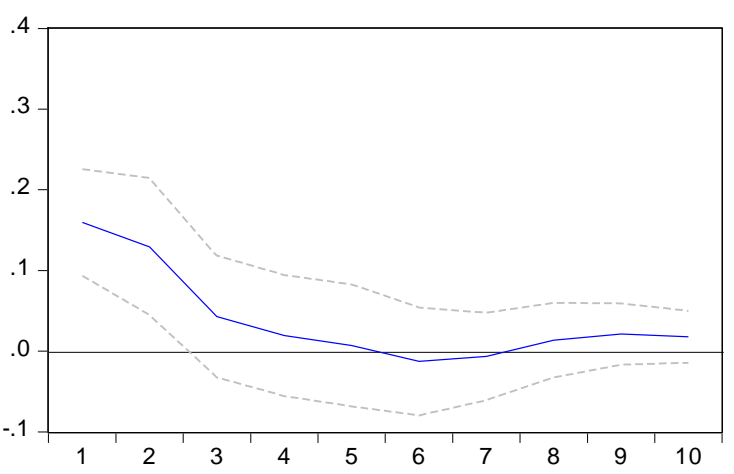

GIRF of $Z$ to $Z$

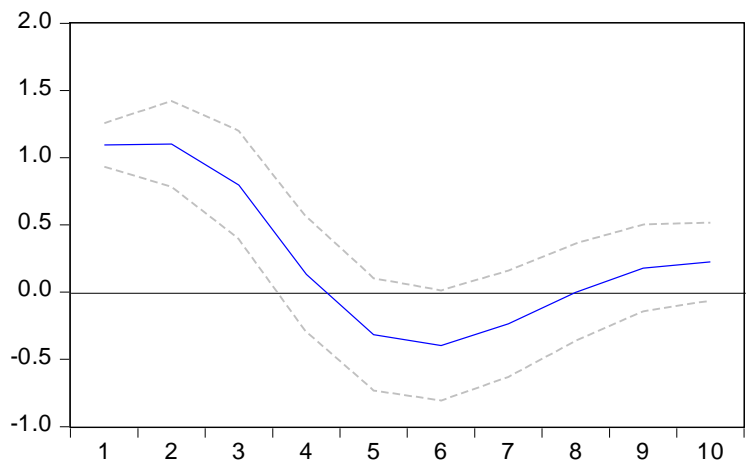

Figure 4. Generalized impulse response functions of $z_{t}$ and $u_{t}$.

We found it necessary to use two lags after using a BIC criterion. Our estimates of (3) and (4) are provided in Table 3. We see that current-period effects estimated at 0.368 and 0.144 are statistically significant indicating that there is a feedback effect between inefficiency and quality. It is well known that in SVAR systems the parameters do not have structural interpretation, so we resort to generalized impulse response functions provided in Figure 4. The off-diagonal generalized impulse responses show a) the effect of a one-standard-deviation shock in $\mathrm{Z}$ on inefficiency (upper left graph) and b) the effect of a one-standard-deviation shock in inefficiency on Z. Both effects are statistically significant as shown by the $95 \%$ error bands. Specifically, the effect of $\mathrm{Z}$ on inefficiency is positive and significant for up to two periods and declines over time. The effect of inefficiency on Z lasts 4-5 years, it is positive, and statistically significant.

Findings suggest, ceteris paribus, the existence of an inertia that may be verified in continuous improvement actions. For instance, airport level measures for reducing flight delays 
may only produce effective results on airline technical efficiency levels in a couple of years. The reverse may also be true, should the airlines adopt benchmarking levels for improving their productive resources in light of the best practices. It may take a couple of years until flight delays can be reduced. Differential measures such as financial incentives could be adopted in airport fares and ticket fees to ensure flight punctuality. New flight control and navigation technologies could be adopted in Chinese airports to allow landings and take-offs on foggy days, thus speeding-up the materialization of the trade-in between technical efficiency and reduction in flight delays.

Table 3: Results for the structural vector auto-regressive model (standard errors - SE - are given within brackets in the subsequent line)

\begin{tabular}{|l|l|l|}
\hline & U equation & $Z$ equation \\
\hline$U_{t-1}$ & 0.664 & 2.301 \\
& $(0.113)$ & $(0.365)$ \\
\hline$U_{t-2}$ & -0.243 & 0.402 \\
& $(0.13303)$ & $(0.43090)$ \\
\hline$Z_{t}$ & 0.368 & --- \\
\hline$Z_{t-1}$ & $(0.127)$ & \\
\hline$Z_{t-2}$ & 0.021 & 0.670 \\
& $(0.03506)$ & $(0.114)$ \\
\hline$Z_{t}$ & -0.026 & -0.277 \\
& $(0.03919)$ & $(0.127)$ \\
\hline$U_{t}$ & 0.023 & --- \\
& $(0.029)$ & \\
\hline
\end{tabular}

\section{Conclusions}


This paper presents an analysis of the efficiency of Chinese airlines during 2006-2014 using a novel SVAR model for technical efficiency and delays. This model makes it possible to compute simultaneously the impact of delays on the residuals of the stochastic distance function, thus presenting a higher discriminatory power, with technical efficiency scores less biased towards one. Results suggest a mutual dependence relationship between airline technical efficiency scores and delays, thus building upon scant previous papers that addressed this issue, treating delays as an undesirable output within the ambit of airport operations.

A failure to include flight delays in airline operations planning may lead to wrong decisions in terms of how much outputs to produce (passengers and cargoes to carry), when to produce them, and how to produce them, yielding higher operational costs to the airlines and lower service levels to its customers. For instance, airlines may decide upon a wrong combination between capital (number of planes) and labor (number of employees), which would have been different if delays were taken into consideration. Flight delays do not only keep airlines stuck on the ground but also require additional ground personnel more intensively to manage customer expectations and relocate passengers to upcoming flights.

Putting the last paragraph into other words, the impact on policy implications suggests that managers and regulators should pay more attention to flight delays when benchmarking the performance of airline companies. In the air transport operations, passenger and cargo transportation will be inevitably associated with flight delays. It is necessary to take account of it so as to improve the unbiased estimation of technical efficiency of airlines and to depict how their scores fluctuate more precisely over the course of time within and between airlines. Additionally, considering the impact of flight delays into the input/output mix will not only help in optimizing airline resource allocation but also in designing customer service measures to remediate the loss of utility caused by them.

As regards the focus of this research, it is possible to affirm that, during recent years, the overall efficiency of Chinese airline companies has tended to decline due to flight delays, hence, the Chinese airline companies should work on plans to stimulate flight punctuality improvement. More research is still needed to further confirm the present conclusions in this paper. Some alternative research venues may include the analysis of contextual variables, assessing how they impact the relationship between efficiency and delays in light of different ownership structures, focus on passenger transportation, fleet mix etc. 


\section{References}

Aaker, J.L., Fournier, S.F., and Brasel, S.A. (2004). When good brands do bad. J. Consum. Res. 31(1), 1-16. doi:10.1086/383419

Assaf, A. (2009). Are US airlines really in crisis? Tour. Manag. 30(6), 916-921. doi:10.1016/j.tourman.2008.11.006

Assaf, A. G., Josiassen, A., \& Gillen, D. (2014). Measuring firm performance: Bayesian estimates with good and bad outputs. J. Bus. Res. 67(6), 1249-1256. doi:10.1016/j.jbusres.2013.04.005

Baltagi, B.H., Griffin, J.M., and Rich, D.P. (1995). Airline deregulation: the cost pieces of the puzzle. Int. Econ. Rev. 36(1) 245-259. doi: 10.2307/2527435.

Barbot, C., Costa, A., and Sochirca, E. (2008). Airlines performance in the new market context: a comparative productivity and efficiency analysis. J. Air Transp. Manag. 14(5) 270-274. doi: 10.1016/j.jairtraman.2008.05.003

Barros, C.P., and Couto, E. (2013). Productivity analysis of European airlines, 2000-2011. J. Air Transp. Manag. 31, 11-13. doi: 10.1016/j.jairtraman.2012.10.006

Barros, C.P., Liang, Q.B., and Peypoch, N. (2013). The technical efficiency of US Airlines. Transp. Res. Part A: Policy and Pract. 50, 139-148. doi: 10.1016/j.tra.2013.01.019

Barros, C.P., and Peypoch, N. (2009). An evaluation of European Airlines' operational performance. Int. J. Prod. Econ. 122(2), 525-533. doi: 10.1016/j.ijpe.2009.04.016

Barros, C.P., and Wanke, P. (2015). An analysis of African airlines efficiency with two-stage TOPSIS and neural networks. J. Air Transp. Manag. 44/45, 90-102. doi:10.1016/j.jairtraman.2015.03.002

Bauer, P.W. (1990). Decomposing TFP growth in the presence of cost inefficiency, nonconstant returns to scale, and technological progress. J. Prod. Anal. 1(4), 287-299. doi: 10.1007/BF00160047

Bilotkach, V., and Huschelrath, K. (2012). Airline alliances and antitrust policy: The role of efficiencies. J. Air Transp. Manag. 21, 76-84. doi: 10.1016/j.jairtraman.2011.12.019

Bitzan, J.D., Peoples, J.H., and Wilson, W.W. (2016) Airline Efficiency (Vol. 5). Bingley, UK: Emerald.

Caves, D.W., Christensen, L.R., and Tretheway, M.W. (1981). US Trunk Air Lines, 1972-1997: a multilateral comparison of total factor productivity. In: T.G. Cowing and R.E. Stevenson (Eds.), Productivity Measurement in Regulated Industries (Chap. 3, pp. 47-77). New York: Academic Press.

Caves, D.W., Christensen, L.R., and Tretheway, M.W. (1984). Economies of density versus economies of scale: why trunk and local service airline costs differ. The RAND J. Econ. 15(4), 471-489.

Chen, Z., Barros, C., and Yu, Y. (2017). Spatial distribution characteristic of Chinese airports: A spatial cost function approach. J. Air Transp. Manag. 59, 63-70. doi:10.1016/j.jairtraman.2016.11.011

Chow, C.K.W. (2010). Measuring the productivity changes of Chinese airlines: the impact of the entries of nonstate owned carriers. J. Air Transp. Manag. 16(6), 320-324. doi:10.1016/j.jairtraman.2010.04.001

Coelli, T.J., Estache, A., Perelman, S., and Trujillo, L. (2003). A primer on efficiency measurement for utilities and transport regulators. Washington DC: World Bank Institute.

Coelli, T., Perelman, S., and Romano, E. (1999). Accounting for environmental influences in stochastic frontier models: with application to international airlines. J. Prod. Anal. 11(3), 251-273. doi: 10.1023/A:1007794121363

Cornwell, C., Schmidt, P., and Sickles, R.C. (1990). Production frontiers with cross-sectional and time-series variation in efficiency levels. J. Econ. 46(1/2), 185-200. doi:10.1016/0304-4076(90)90054-W 
Cui, Q., and Li, Y. (2015). The change trend and influencing factors of civil aviation safety efficiency: The case of Chinese airline companies. Saf. Sci. 75, 56-63. doi:10.1016/j.ssci.2015.01.015

Distexhe, V., and Perelman, S. (1994). Technical efficiency and productivity growth in an era of deregulation: the case of airlines. Swiss J. Econ. Stat. 130(4), 669-689.

Fan, L. W., Wu, F., and Zhou, P. (2014). Efficiency measurement of Chinese airports with flight delays by directional distance function. J. Air Transp. Manag. 34, 140-145. doi:10.1016/j.jairtraman.2013.10.002

Gillen, D.W., Oum, T.H., and Tretheway, M.H. (1990). Airline cost structure and policy implications: a multiproduct approach for Canadian airlines. J. Transp. Econ. Policy, 24(1), 9-34.

Good, D., Nadiri, M., Roller, L.H., and Sickles, R.C. (1993). Efficiency and productivity growth comparisons of European and US air carriers: a first look at the data. J. Prod. Anal. 4, 115-125. doi: 10.1007/BF01073469

Good, D., Roller, L.H., and Sickles, R.C. (1995). Airline efficiency differences between Europe and the US: Implications for the pace of EC integration and domestic regulation. Eur. J. Oper. Res. 80(2), 508-518. doi: 10.1016/0377-2217(94)00134-X.

Gustafsson, A. (2009). Customer satisfaction with service recovery. J. Bus. Res. 62 (11), 1220-1222. doi:10.1016/j.jbusres.2008.11.001

Graham, A. (2008). Airport Planning and regulation in the United Kingdom. In C. Winston \& G. De Rus (Eds.), Aviation infrastructure performance: A study in comparative political economy. Washington DC: Brookings.

Greer, M.R. (2008). Nothing focuses the mind on productivity quite like the fear of liquidation: changes in airline productivity in the United States, 2000- 2004. Transp. Res. Part A: Policy Pract. 42(2), 414-426. doi:10.1016/j.tra.2007.11.001

Greer, M.R. (2009). Is it the labor unions' fault? Dissecting the causes of the impaired technical efficiencies of the legacy carriers in the United States. Transp. Res. Part A: Policy Pract. 43(9/10), 779-789. doi: 10.1016/j.tra.2009.07.007

Inglada, V., Rey, B., Rodriguez-Alvarez, A., and Coto-Millan, P. (2006). Liberalisation and efficiency in international air transport. Transp. Res. Part A: Policy Pract. 40(2), 95-105. doi:10.1016/j.tra.2005.04.006

Jiang, H., and Zhang, Y. (2016). An investigation of service quality, customer satisfaction and loyalty in China's airline market. J. Air Transp. Manag. 57, 80-88. doi:10.1016/j.jairtraman.2016.07.008

Kumbhakar, S.C., and Lovell, C.A.K. (2000). Stochastic Frontier Analysis. Cambridge UK: Cambridge University Press.

Lee, B.L., and Worthington, A.C. (2014). Technical efficiency of mainstream airlines and low-cost carriers: New evidence using bootstrap data envelopment analysis truncated regression. J. Air Transp. Manag. 38, 1520. doi: 10.1016/j.jairtraman.2013.12.013

Lei, Z., and O'Connell, J. F. (2011, October). Aviation policy in China: an analysis of recent developments, eAnalyst (Key Policy Issue). Retrieved from http://www.iata.org/whatwedo/Documents/economics/LeiOConnell-Aviation-Policy-in-China.pdf

Liu, Z., and Lynk, E.L. (1999). Evidence on market structure of the deregulated US airline industry. Appl. Econ. 31(9), 1083-1092. doi:10.1080/000368499323562

Lozano, S., and Gutiérrez, E. (2011). Slacks-based measure of efficiency of airports with airplanes delays as undesirable outputs. Comput. Oper. Res. 38, 1, 131-139. doi:10.1016/j.cor.2010.04.007

Lozano, S., Gutiérrez, E., and Moreno, P. (2013). Network DEA approach to airports performance assessment considering undesirable outputs. Appl. Math. Model. 37(4), 1665-1676. doi:10.1016/j.apm.2012.04.041 
Merkert, R., and Hensher, D.A. (2011). The impact of strategic management and fleet planning on airline efficiency: a random effects Tobit model based on DEA efficiency scores. Transp. Res. Part A: Policy Pract. 45(7), 686-695. doi: 10.1016/j.tra.2011.04.015.

Ouellette, P., Petit, P., Tessier-Parent, L.-P., and Vigeant, S. (2010). Introducing regulation in the measurement of efficiency, with an application to the Canadian air carriers industry. European J. Oper. Res. 200(1), 216-226. doi: 10.1016/j.ejor.2008.11.041

Oum, T.H., and Yu, C. (1995) A productivity comparison of the world's major airlines. J. Air Transp. Manag. 2(3/4), 181-195. doi: 10.1016/0969-6997(96)00007-5

Schmidt, P., Sickles, R.C. (1984). Production frontiers and panel data. J. Bus. Econ. Stat. 2(4), 367-374.

Shaw, S. L., Lu, F., Chen, J., and Zhou, C. (2009). China's airline consolidation and its effects on domestic airline networks and competition. J. Transp. Geogr. 17(4), 293-305. doi:10.1016/j.jtrangeo.2009.02.005

Sjögren, S., and Söderberg, M. (2011). Productivity of airline carriers and its relation to deregulation, privatisation and membership in strategic alliances. Transp. Res. Part E: Logist. Transp. Rev. 47(2), 228-237. doi: 10.1016/j.tre.2010.09.001

Tavassoli, M., Faramarzi, G.R., and Saen, R.F. (2014). Efficiency and effectiveness in airline performance using a SBM-NDEA model in the presence of shared input. J. Air Transp. Manag. 34, 146-153. doi: 10.1016/j.jairtraman.2013.09.001

Tsionas, E.G. (2002). Stochastic frontier models with random coefficients. Journal of Applied Econometrics, $17: 2$, pp. $127-147$.

Tsionas, E.G. (2006). Inference in dynamic stochastic frontier models. J. Appl. Econ. 21 (5), 669-676. doi:10.1002/jae.862

Vlachos, I., and Lin, Z. (2014). Drivers of airline loyalty: Evidence from the business travelers in China. Transp. Res. Part E: Logist. Transp. Rev. 71, 1-17. doi:10.1016/j.tre.2014.07.011

Wang, J., Bonilla, D., and Banister, D. (2016). Air deregulation in China and its impact on airline competition 1994-2012 J. Transp. Geogr. 50, 12-23. doi:10.1016/j.jtrangeo.2015.03.007

Wang, K., Fan, X., Fu, X., and Zhou, Y. (2014). Benchmarking the performance of Chinese airlines: An investigation of productivity, yield and cost competitiveness. J. Air Transp. Manag. 38, 3-14. doi:10.1016/j.jairtraman.2013.12.012

Wanke, P., Barros, C., and Chen, Z. (2015). An analysis of Asian airlines efficiency with two-stage TOPSIS and MCMC generalized linear mixed models. Int. J. Prod. Econ. 169, 110-126. doi:10.1016/j.ijpe.2015.07.028

Wanke, P., Barros, C.P., Nwaogbe, O. R.. (2016a). Assessing productive efficiency in Nigerian airports using Fuzzy-DEA. Transp. Policy, 49, p. 9-19. doi:10.1016/j.tranpol.2016.03.012

Wanke, P., and Barros, C.P. (2016b). Efficiency in Latin American airlines: A two-stage approach combining Virtual Frontier Dynamic DEA and Simplex Regression. J. Air Transp. Manag. 54, 93-103. doi:10.1016/j.jairtraman.2016.04.001

Windle, R.J. (1991). The World's Airlines: a cost and productivity comparison. J. Transp. Econ. Policy, 25, 3149.

Wu, Y., He, C., and Cao, X. (2013). The impact of environmental variables on the efficiency of Chinese and other non-Chinese airlines. J. Air Transp. Manag. 29, 35-38. doi:10.1016/j.jairtraman.2013.02.004

Yu, M-M. (2010). Assessment of airport performance using the SBM-NDEA model. Omega, 38 (6), 440 - 452. doi:10.1016/j.omega.2009.11.003

Yu, M-M. (2004). Measuring physical efficiency of domestic airports in Taiwan with undesirable outputs and environmental factors. J. Air Transp. Manag. 10(5), 295 - 303. doi:10.1016/j.jairtraman.2004.04.001 
Zhang, L., Zhang, L., Zhou, P., and Zhou, D. (2015). A non-additive multiple criteria analysis method for evaluation of airline service quality. J. Air Transp. Manag. 47, 154-161. 